Article

\title{
Ultraviolet Light-degradation Behavior and Antibacterial Activity of Polypropylene/ZnO Nanoparticles Fibers
}

\author{
Guangyu Zhang ${ }^{1}{ }^{\mathbb{D}}$, Yao Xiao ${ }^{1}$, Jiawei Yan ${ }^{2}$, Ningwei Xie ${ }^{1}$, Rong Liu ${ }^{1, *}$ and Yu Zhang ${ }^{1}$ \\ 1 National \& Local Joint Engineering Research Center of Technical Fiber Composites for Safety and Health, \\ School of Textile and Clothing, Nantong University, Nantong 226019, China; zgyu85@ntu.edu.cn (G.Z.); \\ xyt123asd@163.com (Y.X.); ningweixie@163.com (N.X.); z.yu@ntu.edu.cn (Y.Z.) \\ 2 Faculty of Textile Science and Technology, Shinshu University, 3-15-1, Tokida, Ueda, Nagano 386-8567, Japan; \\ 19fs110c@shinshu-u.ac.jp \\ * Correspondence: rong063@ntu.edu.cn; Tel.: +86-513-8501-2837
}

Received: 25 October 2019; Accepted: 5 November 2019; Published: 8 November 2019

\begin{abstract}
Herein, $\mathrm{ZnO}$ nanoparticles (NPs) were synthesized using zinc acetate and an amino hyperbranched polymer. The methods of transmission electron microscope (TEM) and X-ray Diffraction (XRD) were applied to the characterization of ZnO NPs. Polypropylene (PP)/ZnO fiber was prepared using 1-5 wt $\%$ ZnO NPs via melt spinning. The ultraviolet light (UV)-degradation behavior, antibacterial activity and mechanical properties of PP fibers were characterized. The PP fiber filled with ZnO NPs presents better mechanical properties and the resistance to UV light degradation. For the best effect, the contents of $\mathrm{ZnO}$ NPs were set $4 \mathrm{wt} \%$ in PP fiber. FTIR analysis shows significant photo-degradation of PP induced by UV irradiation and a remarkable reduction in the UV degradation of the fiber filled with ZnO NPs. It is also observed that the ZnO NPs-filled fiber has good antibacterial actives against Escherichia coli and staphylococcus aureus.
\end{abstract}

Keywords: $\mathrm{ZnO}$ nanoparticles; polypropylene fiber; ultraviolet light-degradation; antibacterial

\section{Introduction}

Polypropylene (PP) fiber has been extensively applied in the textile industry because of its low cost, high strength, and resistance to chemicals. However, the physical and mechanical properties of PP materials are much susceptible to photo-irradiation. The photo-degradation of PP macromolecules usually results in decreased service life, limiting the application of PP fibers [1-3]. To increase the resistance of PP fibers to ultraviolet rays and the photo-oxidative degradation, organic and inorganic particles were used as fillers for anti-UV applications. Nevertheless, organic UV absorbers are not stable especially at the high temperature and pressure [4-6]. Inorganic materials able to withstand harsh process conditions such as $\mathrm{TiO} 2, \mathrm{ZnO}, \mathrm{MgO}, \mathrm{MMT}$, and $\mathrm{CaO}$ have attracted wide attention. Among them, $\mathrm{ZnO}$ nanoparticles (NPs) have been researched a lot because of their low price, unique physical properties brought by the size effect, and potential applications in UV blocking materials [7-12].

As reported, $\mathrm{ZnO}$ as a filler can not only enhance physical and mechanical properties, but also improve the resistance of PP materials to ultraviolet rays and microorganisms [13-15]. More recently, the antimicrobial properties of $\mathrm{ZnO}$ NPs have been discovered. Compared with silver NPs, $\mathrm{ZnO}$ NPs are expected to provide more affordable and safe solutions in the future [13,16-18]. Zhao et al. studied the photodegradation characteristics of PP materials filled with ZnO NPs. The evolution of the carbonyl absorption band at $1780 \mathrm{~cm}^{-1}$ obtained by FTIR analysis showed that UV irradiation was more likely to cause obvious photodegradation of PP [1]. Karami et al. [14] investigated the impacts of UV-irradiation exposure on the structure and properties of ZnO NPs-filled PP fibers. 
Both carbonyl and hydroperoxide indexes were found increasing due to the growing UV-irradiation exposure time; moreover, PP nanocomposite fibers achieved a smaller increase in these indexes than unfilled PP fibers. Yoann et al. [19] used ZnO NPs as a fungicide to synthesize antibacterial PP surfaces. The ZnO-functionalized substrate exhibited an antibacterial response in Escherichia coli (E. coli) and the antibacterial activity of ZnO-PP was significantly higher than pure PP.

Notably, ZnO NPs with large specific surface area and high surface energy are difficult to disperse homogenously, leading to agglomeration [20-22]. In our previous study, an amino hyperbranched polymer (HSDA) was synthesized and used to control the synthesis of ZnO NPs. It also served as a binder to impart and fix the NPs on cellulose fabric, thereby presenting antimicrobial properties $[23,24]$. This research work is mainly aimed to synthesize high dispersion ZnO NPs, to develop PP/ZnO nanocomposite fibers by melt spinning, and to investigate UV light-degradation stability, antibacterial and mechanical properties of the prepared fibers.

\section{Materials and Methods}

\subsection{Materials}

Polypropylene powder (F401 melting temperature $163^{\circ} \mathrm{C}$ ) used was from Yangzi Petrochemical (Yangzhou, China). Zinc acetate, lithium hydrate, and ethyl alcohol (95\%) were purchased from Guoyao Chemical Technology Co., Ltd. Shanghai, China. The hyperbranched polymers (HBP) were prepared as described in our previous paper [23].

\subsection{Preparation of $\mathrm{ZnO} \mathrm{NPS}$}

Zinc acetate (1.83 g) was completely dissolved in $100 \mathrm{~mL}$ of the ethanol solution (95\%), refluxed at $80^{\circ} \mathrm{C}$ in the flask. After the HBP with a concentration of $2 \mathrm{~g} / \mathrm{L}$ was added, the mixture was stirred in a magnetic stirrer for $3 \mathrm{~h}$. Then the lithium hydroxide ethanol solution $(50 \mathrm{~mL}, 0.1 \mathrm{~mol} / \mathrm{L})$ was added dropwise into the solution, stirred for $2 \mathrm{~h}$ until the transparency aqueous solution turned into milky white. Finally, $\mathrm{ZnO}$ precipitate was produced using a centrifuge at 12,000 rpm for $10 \mathrm{~min}$.

\subsection{Preparation of $P P / Z n O N P s$ Fiber}

$\mathrm{ZnO}$ NPs and PP granules were dried at $90{ }^{\circ} \mathrm{C}$ for $8 \mathrm{~h}$ before the PP/ZnO NPs were melt compounded using a twin-screw extruder (KS220 L/D = 26, Ruiming Co., Ltd., Wuhan, China) at a temperature of $160^{\circ} \mathrm{C}$ and a screw rate of $100 \mathrm{rpm}$. The fiber passed over the godets at a constant draw ratio $(\lambda=4)$. The concentrations of $\mathrm{ZnO}$ NPs in PP granules were $1 \%-5 \%$, respectively. A sample of PP was prepared under the same conditions without adding NPs for reference.

\subsection{Characterization of $\mathrm{ZnO} N P s$}

The morphology and lattice characteristics of ZnO NPs were characterized by transmission electron microscopy (TEM) (2010, JEOL, Tokyo, Japan). The crystalline phases of ZnO NPs were analyzed by X-ray diffraction (XRD) (Philips, Amsterdam, The Netherlands) via a CuK $\alpha$ X-ray source at a voltage and current of $40 \mathrm{kV}$ and $30 \mathrm{~mA}$ respectively. The UV absorption properties of ZnO NPs were determined by ultraviolet-visible (UV-vis) spectroscopy (UV-3010 Hitachi, Tokyo, Japan).

\subsection{Characterization of $\mathrm{ZnO} N P s$-Filled PP Fibers}

To characterize the photo-degradation behavior, PP and ZnO NPs-filled fibers were exposed to $300 \mathrm{~W}$ ultraviolet light (ULTRA-VITALUX, Munich, Germany) for $72 \mathrm{~h}, 96 \mathrm{~h}$ and $120 \mathrm{~h}, 35 \mathrm{~cm}$ away from the light source. The surface morphology of fibers was characterized by scanning electron microscopy (SEM) (6510, JEOL, Tokyo, Japan) and energy dispersive spectroscopy (EDS) (Carl Zeiss, EVO 15, Oberkochen, Germany). The tensile properties of $\mathrm{pp}$ and $\mathrm{PP} / \mathrm{ZnO}$ fibers were studied by Instron 5969 (Boston, Massachusetts, USA) following the ASTM D3822 standard. The sample with a length of $20 \mathrm{~mm}$ was stretching between the clips of the tensile tester with a rate of $20 \mathrm{~mm} / \mathrm{min}$ until 
the fiber was ruptured. To characterize the UV-oxidative degradation of PP and PP/ZnO fibers, FT-IR (Nicolet, Thermo Scientific, Madison, WI, USA) method was used to measure the carbonyl group on fiber. The spectra were recorded in the range from 400 to $4000 \mathrm{~cm}^{-1}$.

DSC (Q-50, TA Instruments, Newcastle, DE, USA) measurement was performed as follows. The PP and $\mathrm{ZnO} / \mathrm{PP}$ fiber $(<10 \mathrm{mg})$ was chopped and placed in a crucible. Under nitrogen protection, the temperature was firstly reduced from normal state to $-20^{\circ} \mathrm{C}$ at a rate of $10 \mathrm{~K} / \mathrm{min}$ and then heated to $200{ }^{\circ} \mathrm{C}$. After $5 \mathrm{~min}$, the same cooling rate was maintained. The temperature was dropped to $-20^{\circ} \mathrm{C}$ to eliminate heat history. Then it was again raised from $-20{ }^{\circ} \mathrm{C}$ to $400{ }^{\circ} \mathrm{C}$ at $10 \mathrm{~K} / \mathrm{min}$, and the secondary heating curve of the fiber was measured. The percentage of crystalline fraction was calculated from these enthalpies as:

$$
x=\frac{\Delta H_{f}}{\left(1-\varphi_{p}\right) \times \Delta H_{f}^{\circ}}
$$

where $\varphi_{\mathrm{p}}$ is the weight ration of $\mathrm{ZnO}$ NPs in PP fibers and $\Delta \mathrm{H}^{\circ} \mathrm{f}$ is the reference melting enthalpy of PP $\left(207 \mathrm{~J} \mathrm{~g}^{-1}\right)$.

The antimicrobial activity of ZnO NPs-filled fibers was tested against $E$. coli and S. aureus using a shaking flask method following GB/T20944.3-2008 (China) [24].

\section{Results}

\subsection{Characterization of $\mathrm{ZnO} N P s$}

The principle of synthesizing amino-capped ZnO NPs is illustrated in Scheme 1. The solution of hyperbranched polymers was added into the $\mathrm{Zn}(\mathrm{Ac})_{2}$ ethanol solution in alkaline medium followed by the hydrothermal reaction. Under alkaline conditions, $\mathrm{Zn}^{2+}$ can be converted to $\mathrm{Zn}(\mathrm{OH})_{2}$ colloid. In the hydrothermal process, $\mathrm{Zn}(\mathrm{OH})_{2}$ colloid dissolves to form $\mathrm{Zn}(\mathrm{OH})_{4}{ }^{2-}$ and $\mathrm{ZnO}$ spontaneously nucleates from $\mathrm{Zn}(\mathrm{OH})_{4}{ }^{2-}$ solution to form multinuclear aggregates. HBP, with a special structure of internally sealed polymer nanocage, will impede the growth of ZnO NPs and protect them from agglomeration $[25,26]$. In this way, the size of $\mathrm{ZnO} N P s$ can be controlled and the prepared $\mathrm{ZnO}$ NPs/PNP hybrid materials obtain good stability in solution.

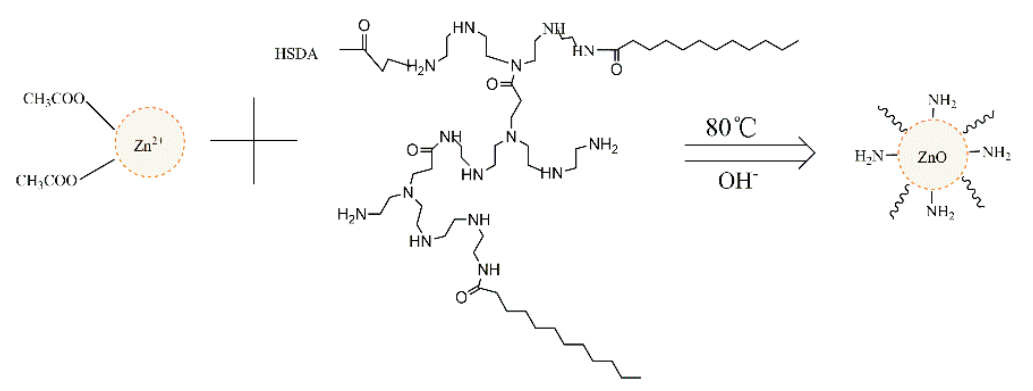

Scheme 1. Schematic illustration of synthesis of amino-capped ZnO NPs.

TEM, SAED, XRD, and UV-vis were used to evaluated the ZnO NPs property. Figure 1a shows the TEM image of the sample, from which numerous NPs with irregular rod morphology can be clearly distinguished. The diameter of amino caped ZnO NPs is about $100 \mathrm{~nm}$. A series of diffraction rings appear in a pattern of the selected area electron diffraction (SAED), as presented in Figure $1 b$, indicating the crystalline phase of amino-capped ZnO NPs. The XRD pattern confirms the wurtzite structure of ZnO NPs. As shown in Figure 1c, all the peaks of (100), (002), (102), (110), (103) and (112) can be indexed to the planes of wurtzite $\mathrm{ZnO}$ and in good agreement with JCPDS data card (36-1451) [27,28]. Interestingly, there is no additional peak corresponding to other impurities in the pattern, implying the obtained ZnO NPs are purely crystalline. The UV absorption properties of ZnO NPs were investigated by UV-Vis spectroscopy, with results in Figure 1d. Compared with the HBP solution, there is a new 
absorption peak at $340 \mathrm{~nm}$ and the prepared ZnO NPs exhibit a strong absorption between $200-400 \mathrm{~nm}$, demonstrating the generation of ZnO NPs [23,29].
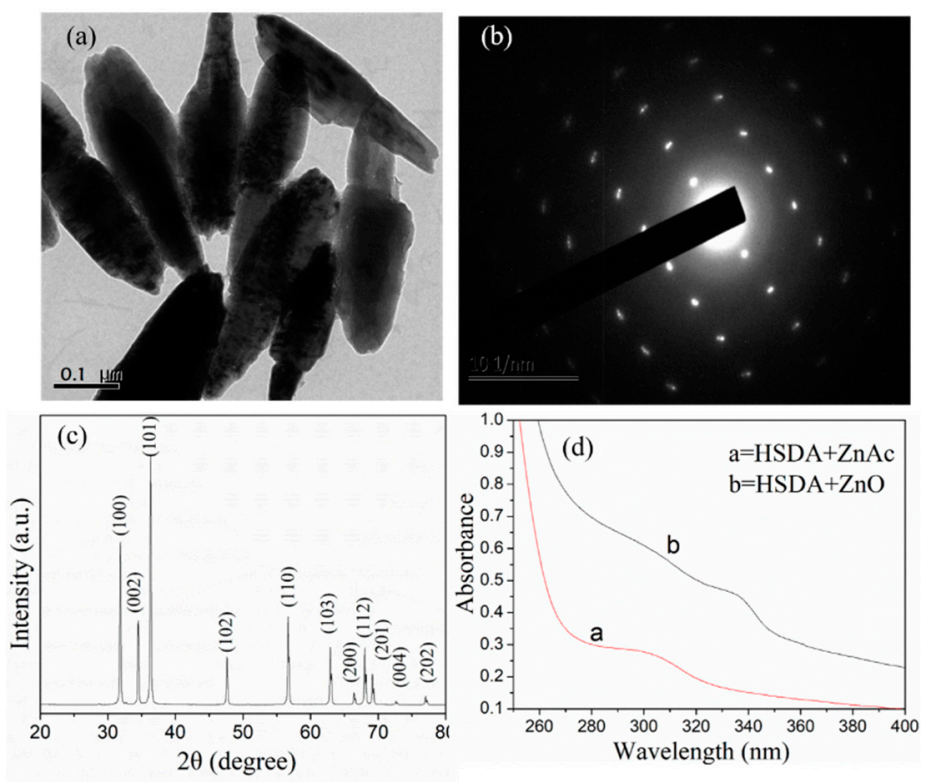

Figure 1. (a) TEM images; (b) selected area electron diffraction (SAED); (c) XRD and (d) UV-vis spectra of $\mathrm{ZnO}$ NPs.

\subsection{Preparation and Mechanical Properties of PP/ZnO Composites:}

The principle of preparing the ZnO NPs-filled PP fiber is described in Scheme 2. The dispersion of inorganic NPs filled in thermos polymers is much hard, as the inorganic NPs are more likely to be agglomerated $[10,30]$. To overcome this problem, we synthesized high dispersion $\mathrm{ZnO}$ NPs and used it for the modified pp fiber. To verify the strength and UV-degradation behavior of ZnO NPs-filled PP fibers, a test was performed on the tensile strength of PP fiber and ZnO NPS-filled PP fiber exposed to UV-light, as shown in Figure 2. The results indicate that the strength of PP fiber increases from $4.2 \mathrm{cN} / \mathrm{dtex}$ to $4.8 \mathrm{cN} / \mathrm{dtex}$ with the rising content of $\mathrm{ZnO} \mathrm{NPs}$ in PP fiber from $1 \%$ to $4 \%$. As the content grows to $5 \%$, the strength of PP fiber experiences slighly decreases, since $\mathrm{ZnO} N P$ s enhance the toughening effect on PP composite fibers. The nano zinc oxide particles have a small size and a large specific surface area, and a combination of physical and chemical polymer chains is generated when the nanoparticles are blending with the polymer. Thereby, the adhesion between the particles and the polypropylene can be further improved. When the added mass fraction of nanoparticles is large, the range of the flexible interface layer inside the polymer fiber gets increased; when subject to an external force, the internal interface layer will be destroyed before the substrate is damaged, which in turn leads to a decrease in the fiber strength $[10,13]$.

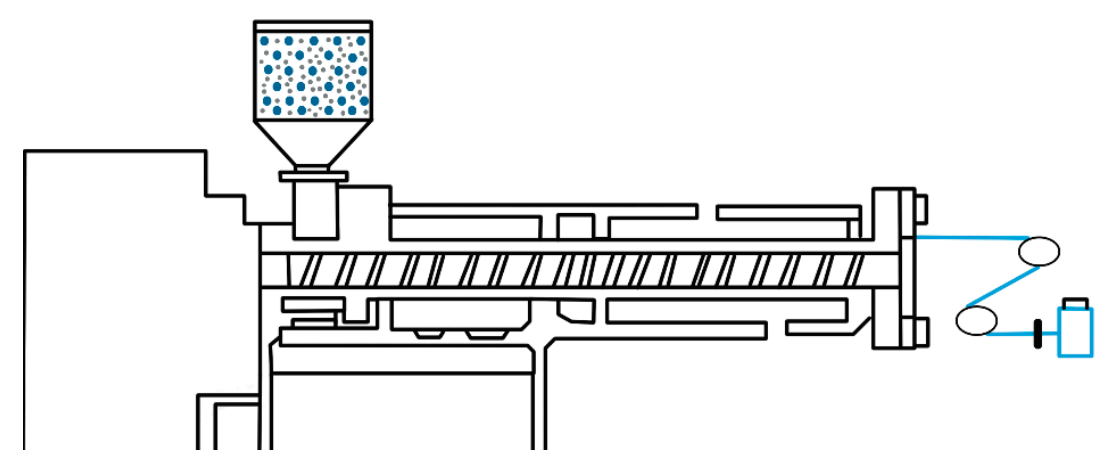

Scheme 2. Schematic illustration of synthesis of ZnO NPs-filled fiber. 

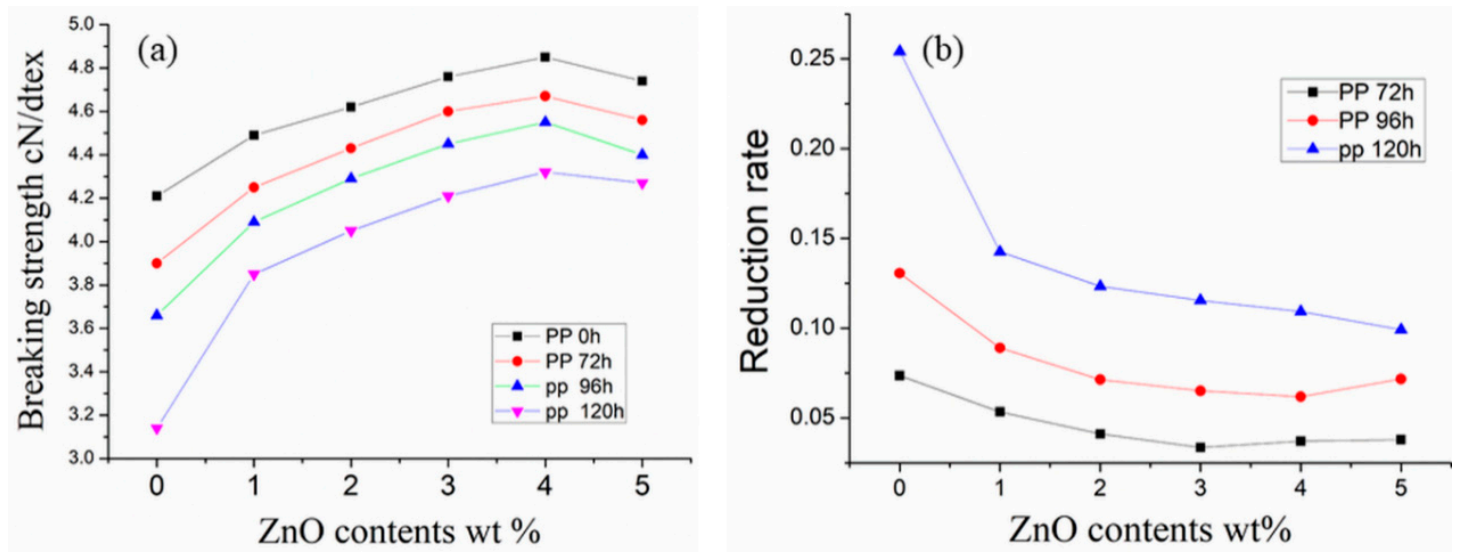

Figure 2. (a) Breaking strength of polypropylene (PP) and ZnO NPs-filled PP with different UV-light exposure time (b) Breaking strength rate of PP fiber with different UV-light exposure time.

Owing to a large number of unstable tertiary carbon atoms in the PP molecule, the tensile strength of PP fibers was reduced after being exposed to the UV-light. To examine the UV-light degradation properties of PP fibers, PP and ZnO NPs-filled PP fibers were exposed to UV-light irradiation from $72 \mathrm{~h}-120 \mathrm{~h}$. The results show that as the content of ZnO NPs in PP fiber increases from 0 to $5 \%$, the fiber strength is declined from $25 \%$ to $10 \%$ under $120 \mathrm{~h}$ of UV-light irradiation. With the UV-light and oxygen, the energy can be used to put the tertiary carbon atom; after the removal of hydrogen, the tertiary carbon radicals become the starting active center, thus breaking the macromolecular chain. When the ZnO NPs-filled fiber is irradiated by UV light, the nano zinc oxide shields against part of the UV light, improving the resistance of the ZnO NPs-filled fiber to the UV light.

\subsection{SEM Images of PP and $\mathrm{ZnO} N P s-F i l l e d$ PP Fibers}

The surface of PP and ZnO NPs fibers were examined by SEM and EDS to determine the distribution of $\mathrm{ZnO}$ NPs on PP fibers. PP and ZnO NPs-filled fibers with different contents are shown in Figure 3. The smooth surface of PP fiber can be clearly found in Figure 3a. SEM images of $\mathrm{ZnO}$ NPs-filled PP fibers, as shown in Figure $3 \mathrm{~b}-\mathrm{d}$, change with the distribution of $\mathrm{ZnO}$ NPs. Some aggregations are observed in the fibers filled with $4 \%$ of ZnO NPs, as illustrated in Figure 3d. It indicates partial aggregation of $\mathrm{ZnO} N$ Ps during the preparation of $\mathrm{ZnO}$ NPs-filled fibers.
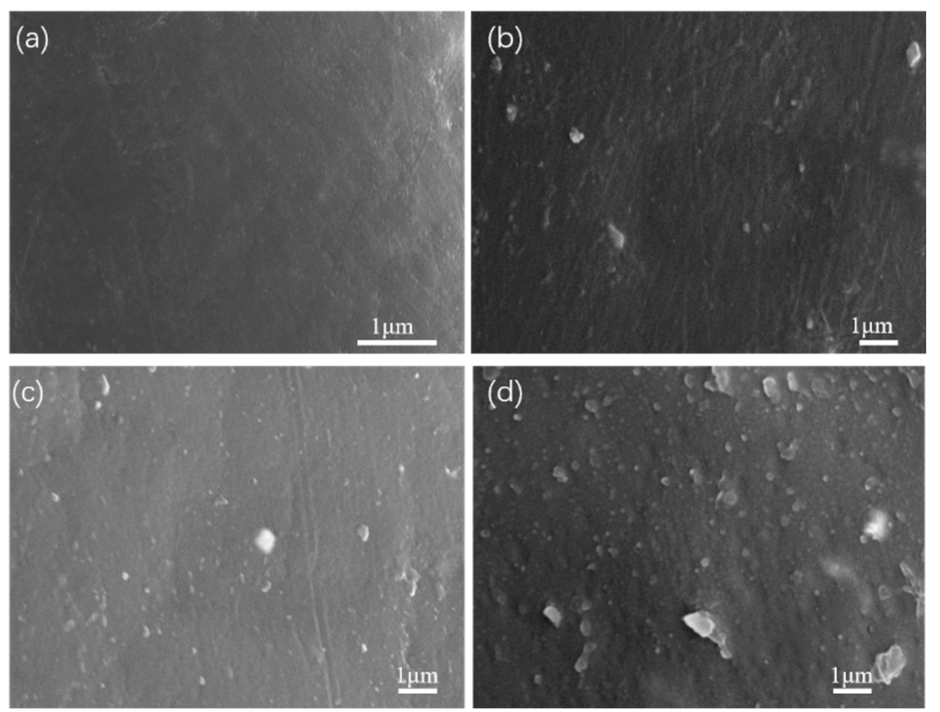

Figure 3. SEM images of (a) PP and ZnO NPs-filled PP fibers with concentration of $2 \%$ (b) $3 \%$ (c) $14 \%$ (d). 
To verify the materials of PP fibers, EDS was used to determine the chemical composition of the prepared fibers. Figure 4 presents the EDS of $4 \mathrm{wt} \% \mathrm{ZnO}$-filled PP. In addition to $\mathrm{C}$ and $\mathrm{O}, \mathrm{Zn}$ can also be observed, indicating the presence of $\mathrm{ZnO}$ on the surface of PP fibers.

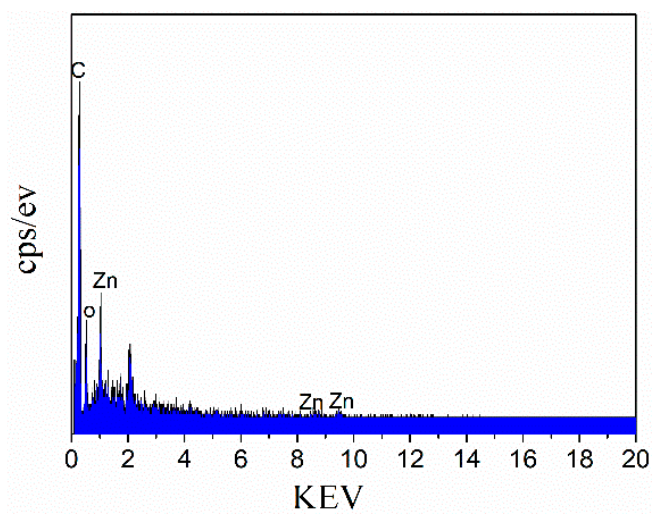

Figure 4. EDS analyses of $4 \mathrm{wt} \% \mathrm{ZnO}$ NPs-filled fibers.

\subsection{Differential Scanning Calorimetry Results}

DSC measurement was performed to investigate crystallization and melting behaviors of $\mathrm{ZnO}$ NPs-filled fibers. DSC thermograms and melting temperatures of PP and ZnO NPs-filled fibers are shown in Figure 5 and Table 1, respectively.

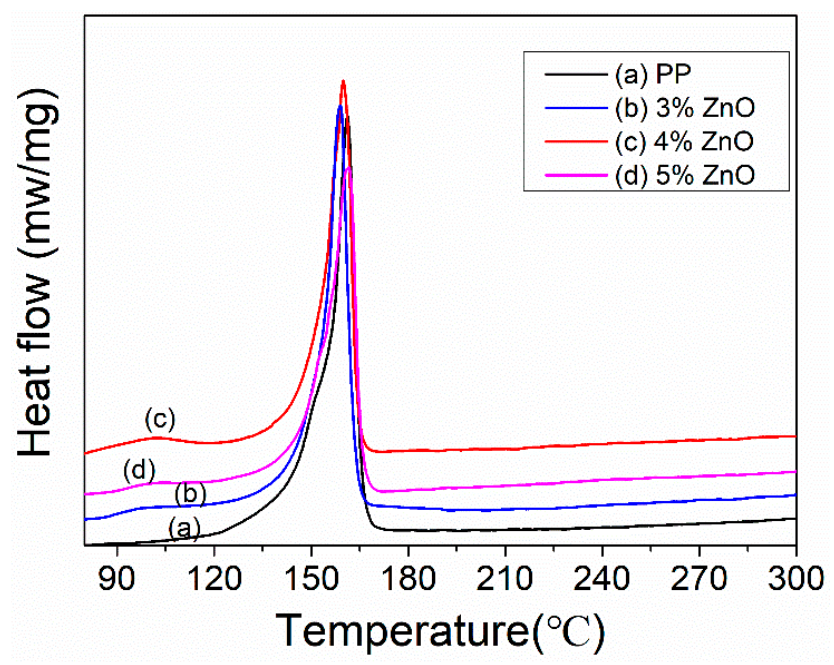

Figure 5. DSC thermograms of (a) pure PP (b) $3 \% \mathrm{ZnO}$-filled fiber (c) $4 \% \mathrm{ZnO}$-filled fiber (d) $5 \%$ ZnO-filled fiber.

Table 1. Thermal properties of the samples obtained from DSC.

\begin{tabular}{|c|c|c|c|}
\hline Sample & $\begin{array}{l}\text { Melting Temperature } \\
\text { (Tm) }\left({ }^{\circ} \mathrm{C}\right)\end{array}$ & $\begin{array}{l}\text { Melting Enthalpy } \\
(\Delta \mathrm{Hm})\left(\mathrm{Jg}^{-1}\right)\end{array}$ & Crystalline Ratio (\%) \\
\hline PP & 162.16 & 90.14 & 43.75 \\
\hline $\mathrm{PP} / \mathrm{ZnO} 3 \%$ & 162.78 & 92.05 & 44.46 \\
\hline $\mathrm{PP} / \mathrm{ZnO} 4 \%$ & 162.25 & 92.38 & 44.62 \\
\hline $\mathrm{PP} / \mathrm{ZnO} 5 \%$ & 162.18 & 91.22 & 44.06 \\
\hline
\end{tabular}

Crystallinity of PP fiber grows with the increasing content of ZnO NPs and reaches the maximum at $4 \mathrm{wt} \%$. The crystallinity of pure fiber, $3 \mathrm{wt} \% \mathrm{ZnO}$ NPs-filled fiber and $4 \mathrm{wt} \% \mathrm{ZnO}$ NPs-filled fiber are obtained to be $43.75 \%, 44.46 \%$ and $44.62 \%$, respectively. It demonstrates that $\mathrm{ZnO} N P s$ can increase 
the crystallization of PP fiber and function as heterogeneous nucleation [10]. For explanation, $\mathrm{ZnO}$ NPs agglomerates will be heterogeneously nucleated after reaching a certain size, thus increasing the crystallization rate of PP. As the content of ZnO NPs increases to $5 \mathrm{wt} \%$, the fiber's crystallinity reaches $44.06 \%$. It is generally accepted that the aggregates of ZnO NPs are able to hinder crystal growth and thus reduce crystallinity [14].

\subsection{FTIR Analysis of PP and ZnO NPs Filled PP Fiber with UV Irradiation}

The PP materials are known to be sensitive to the wavelength of over $300 \mathrm{~nm}$, including sunlight and UV light. The photo-degradation of PP materials is invisible and results in the formation of hydroperoxides and carbonyl species. The degradation $\mathrm{C}=\mathrm{O}$ radical group absorption peaks are found by the FTIR method to be near the wavenumber of $1700 \mathrm{~cm}^{-1}$. The photo-degradation degree of PP fiber is closely correlated to the carbonyl content: the smaller the carbonyl content, the low degradation rate the PP fiber. As depicted in Figure 6a, for the pure pp fiber exposed to UV-light for $72 \mathrm{~h}$ and $120 \mathrm{~h}$, the absorption peak appears at $1726 \mathrm{~cm}^{-1}$. The PP fiber exposed to $120 \mathrm{~h}$ of UV-light presents a stronger peak than the fiber exposed to $72 \mathrm{~h}$ of UV-light. It verifies that the degradation degree of PP fiber has a positive relationship with the time of UV-light irradiation. For the fiber filled with $\mathrm{ZnO}$ NPs, as shown in Figure $6 \mathrm{~b}$, the absorption peak at $1726 \mathrm{~cm}^{-1}$ has no obvious change, confirming that ZnO NPs can inhibit the UV-light degradation of PP fibers.
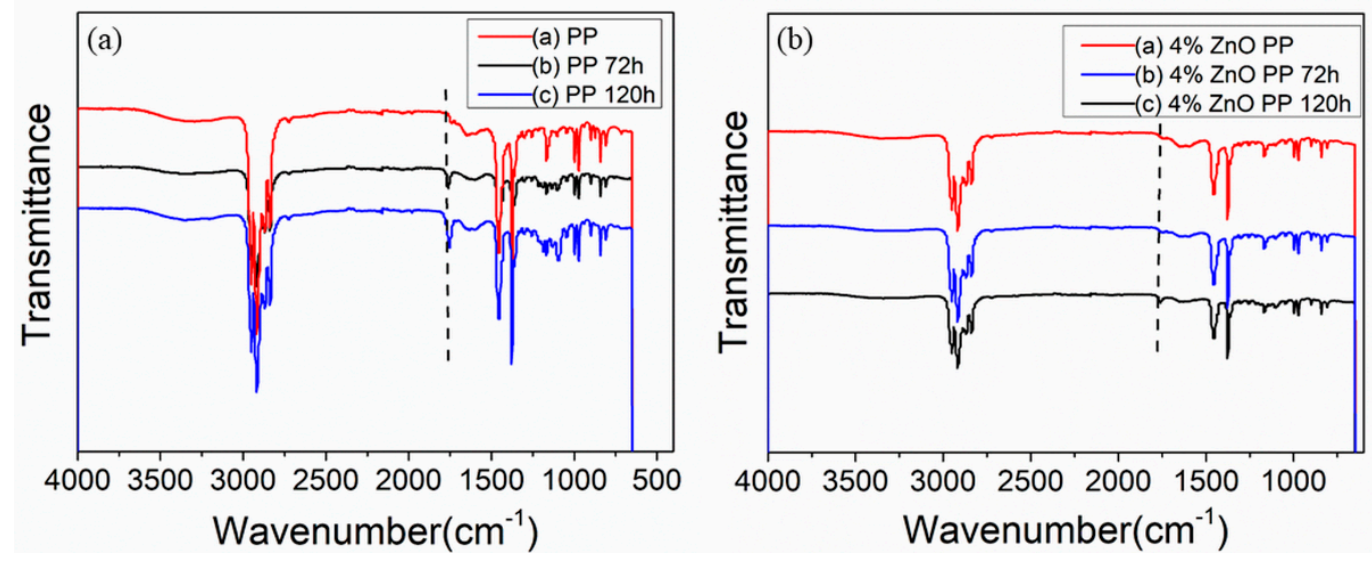

Figure 6. FTIR spectra for (a) pure pp (b) $4 \mathrm{wt} \%$ ZnO NPs-filled pp exposed to UV-light for $0,72 \mathrm{~h}$ and $120 \mathrm{~h}$.

\subsection{Antibacterial Activity of $\mathrm{ZnO} N \mathrm{NP}_{\text {-Filled PP Fiber }}$}

The antimicrobial activity of $\mathrm{ZnO}$ NPs-filled fibers was evaluated by calculation of the percentage reduction in E.coli and S. aureus colonies. With pure PP fiber as control, the results are listed in Table 2. Pure PP samples show no antibacterial properties against both E.coli and S. aureus. By contrast, ZnO NPs-filled PP fibers exhibit good antibacterial activities. Specifically, when the contents of ZnO NPs increase 3\% and more, the bacterial reduction rates of both $S$. aureus and E. coli reach above $99 \%$.

Table 2. Antibacterial activity of ZnO NPs-filled PP fiber.

\begin{tabular}{ccccc}
\hline \multirow{2}{*}{ Sample } & \multicolumn{2}{c}{ S. aureus } & \multicolumn{2}{c}{ E. coli } \\
\cline { 2 - 5 } & $\begin{array}{c}\text { Surviving Cells } \\
\text { (CFU/mL) }\end{array}$ & Reduction (\%) & $\begin{array}{c}\text { Surviving Cells } \\
\text { (CFU/mL) }\end{array}$ & Reduction (\%) \\
\hline Pure fiber & $1.47 \times 10^{6}$ & - & $2.3 \times 10^{5}$ & - \\
1\% ZnO filled fiber & $7.5 \times 10^{5}$ & 64.6 & $1.2 \times 10^{5}$ & 47.85 \\
2\% ZnO filled fiber & $1.1 \times 10^{5}$ & 92.51 & $2.6 \times 10^{4}$ & 88.7 \\
$3 \%$ ZnO filled fiber & $2.4 \times 10^{3}$ & 99.83 & $1.6 \times 10^{3}$ & 99.3 \\
$4 \%$ ZnO filled fiber & $7.2 \times 10^{2}$ & 99.9 & $6.5 \times 10^{2}$ & 99.71 \\
\hline
\end{tabular}


Zhang et al. reported that a PLA film containing 3\% ZnO NPs has antibacterial activity for S. aureus and E. coli and the inhibition rate was $60 \%$ and $58 \%$, respectively. [31] Silvestre et al. reported that PP composites containing 5\% ZnO NPs has 85.3 percent reduction of E. coli with $24 \mathrm{~h}$. [17] However, in our study, the $3 \% \mathrm{ZnO}$ NPs filled PP fiber showed better bactericidal efficacy against S. aureus and E.coli, the inhibition rate more than $99 \%$.The antimicrobial mechanism of ZnO NPs-filled PP fiber can be explained from two aspects seen in Scheme 3. Generally, bacteria are negatively charged, which can be adsorbed by positively charged amino HBP via electrostatic adhesion. The direct interaction of HBP-ZnO NPs with bacteria will result in cell inactivation by disrupting the integrity of the cell membrane. In addition, under light irradiation, $\mathrm{ZnO}$ NPs on the surface of PP fibers generate reactive oxygen species, contributing to the decomposition and damage of bacterial cells.

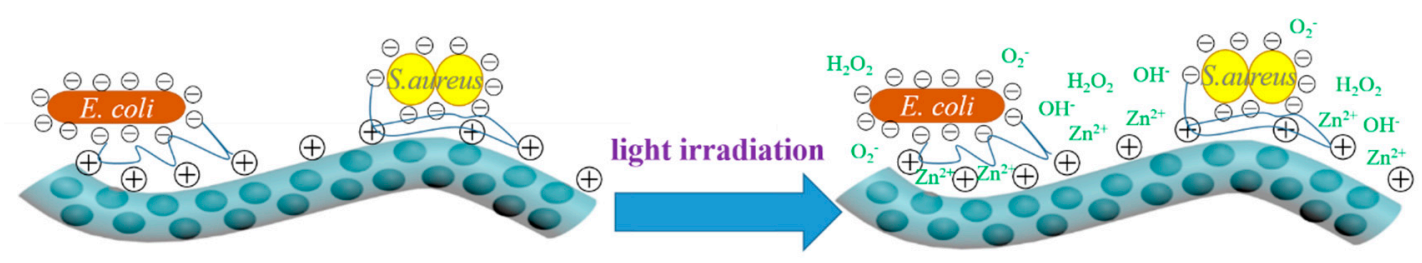

ZnO NPs filled PP fiber

Scheme 3. Antimicrobial mechanism ZnO NPs filled fiber.

\section{Conclusions}

In this paper, the amino capped ZnO NPs were obtained by simply using amino HBP and zinc acetate. ZnO NPs-filled PP fibers were prepared by melt spinning. Moreover, the morphology, thermal property, UV-light degradation behavior, antibacterial activity and mechanical properties of $\mathrm{ZnO}$ NPs-filled fibers were determined. The results show the improvement in the mechanical properties, resistance to UV-light degradation and antibacterial activity of ZnO NPs-filled fiber. In particular, the PP fiber with $4 \mathrm{wt} \% \mathrm{ZnO}$ NPs is proved to be the optimum selection for PP modification.

Author Contributions: Conceptualization, R.L. and G.Z.; Methodology, Y.X. and Y.Z.; Investigation, Y.X.; Software, J.Y. and N.X.; Writing-Original Draft Preparation, G.Z. and L.R.; Project Administration, Y.Z.; Funding Acquisition, G.Z. and Y.Z. All authors read and approved the final manuscript.

Funding: The present work was supported financially by the National Key Research and Development Program of China (No. 2016YFB0303101), National Natural Science Foundation of China (No. 51503105).

Conflicts of Interest: The authors declare that they have no competing interests.

\section{References}

1. Zhao, H.; Li, R.K. A study on the photo-degradation of zinc oxide ( $\mathrm{ZnO})$ filled polypropylene nanocomposites. Polymer 2006, 47, 3207-3217. [CrossRef]

2. Zapata, P.A.; Zenteno, A.; Amigó, N.; Rabagliati, F.M.; Sepúlveda, F.; Catalina, F.; Corrales, T. Study on the photodegradation of nanocomposites based on polypropylene and TiO2 nanotubes. Polym. Degrad. Stab. 2016, 133, 101-107. [CrossRef]

3. Zaman, H.U.; Hun, P.D.; Khan, R.A.; Yoon, K.-B. Morphology, mechanical, and crystallization behaviors of micro-and nano-ZnO filled polypropylene composites. J. Reinf. Plast. Compos. 2012, 31, 323-329. [CrossRef]

4. Aloui, F.; Ahajji, A.; Irmouli, Y.; George, B.; Charrier, B.; Merlin, A. Inorganic UV absorbers for the photostabilisation of wood-clearcoating systems: Comparison with organic UV absorbers. Appl. Surf. Sci. 2007, 253, 3737-3745. [CrossRef]

5. Bojinov, V.B.; Georgiev, N.I.; Marinova, N.V. Design and synthesis of highly photostable fluorescence sensing 1,8-naphthalimide-based dyes containing s-triazine UV absorber and HALS units. Sens. Actuators B Chem. 2010, 148, 6-16. [CrossRef]

6. Nasu, A.; Otsubo, Y. Rheology and UV-protecting properties of complex suspensions of titanium dioxides and zinc oxides. J. Colloid Interface Sci. 2007, 310, 617-623. [CrossRef] 
7. Li, T.; Li, B.; Ji, Y.; Wang, L. Luminescent and UV-Shielding ZnO Quantum Dots/Carboxymethylcellulose Sodium Nanocomposite Polymer Films. Polymers 2018, 10, 112. [CrossRef]

8. Wang, Z. Foaming behaviour of microcellular foam short carbon fibres/polypropylene/nano-CaCO3composites. Plast. Rubber Compos. 2014, 43, 130-137.

9. Pavasupree, S.; Dubas, S.T.; Rangkupan, R. Surface modification of polypropylene non-woven fibers with $\mathrm{TiO} 2$ nanoparticles via layer-by-layer self assembly method:Preparation and photocatalytic activity. J. Environ. Sci. 2015, 37, 59-66. [CrossRef]

10. Mei, L.; Gu, L.; Jiang, J.; Zhang, Z.; Xin, D.; Mai, K. Ultraviolet Resistance and Antimicrobial Properties of ZnO in the Polypropylene Materials: A Review. J. Mater. Sci. Technol. 2015, 31, 331-339.

11. Sawai, J. Quantitative evaluation of antibacterial activities of metallic oxide powders $(\mathrm{ZnO}, \mathrm{MgO}$ and $\mathrm{CaO})$ by conductimetric assay. J. Microbiol. Methods 2003, 54, 177-182. [CrossRef]

12. Zeng, A.; Zheng, Y.; Yong, G.; Qiu, S.; Lei, C. Effect of tetra-needle-shaped zinc oxide whisker (T-ZnOw) on mechanical properties and crystallization behavior of isotactic polypropylene. Mater. Des. 2012, 34, 691-698. [CrossRef]

13. Erem, A.D.; Ozcan, G.; Skrifvars, M. In vitro assessment of antimicrobial polypropylene/zinc oxide nanocomposite fibers. Text. Res. J. 2013, 83, 2152-2163. [CrossRef]

14. Karami, Z.; Youssefi, M.; Borhani, S. The effects of uv irradiation exposure on the structure and properties of polypropylene/zno nanocamposite fibers. Fibers Polym. 2013, 14, 1627-1634. [CrossRef]

15. Esthappan, S.K.; Sinha, M.K.; Katiyar, P.; Srivastav, A.; Joseph, R. Polypropylene/zinc oxide nanocomposite fibers: Morphology and thermal analysis. J. Polym. Mater. 2013, 30, 79.

16. Huang, Y.; Wang, T.; Zhao, X.; Wang, X.; Zhou, L.; Yang, Y.; Liao, F.; Ju, Y. Poly (lactic acid)/graphene oxide-ZnO nanocomposite films with good mechanical, dynamic mechanical, anti-UV and antibacterial properties. J. Chem. Technol. Biotechnol. 2015, 90, 1677-1684. [CrossRef]

17. Silvestre, C.; Cimmino, S.; Pezzuto, M.; Marra, A.; Ambrogi, V.; Dexpertghys, J.; Verelst, M.; Augier, S.; Romano, I.; Duraccio, D. Preparation and characterization of isotactic polypropylene/zinc oxide microcomposites with antibacterial activity. Polym. J. 2013, 45, 938-945. [CrossRef]

18. Ye, X.; Wang, H.; Zheng, K.; Wu, Z.; Zhou, H.; Tian, K.; Su, Z.; Tian, X. The interface designing and reinforced features of wood fiber/polypropylene composites: Wood fiber adopting nano-zinc-oxide-coating via ion assembly. Compos. Sci. Technol. 2016, 124, 1-9. [CrossRef]

19. Rancourt, Y.D.; Couturaud, B.; Mas, A.; Robin, J.J. Synthesis of antibacterial surfaces by plasma grafting of zinc oxide based nanocomposites onto polypropylene. J. Colloid Interface Sci. 2013, 402, 320-326. [CrossRef]

20. Li, W.; Li, L.; Cao, Y.; Lan, T.; Chen, H.; Qin, Y. Effects of PLA film incorporated with ZnO nanoparticle on the quality attributes of fresh-cut apple. Nanomaterials 2017, 7, 207. [CrossRef]

21. Lepot, N.; Bael, M.K.V.; Rul, H.V.D.; D'Haen, J.; Peeters, R.; Franco, D.; Mullens, J. Influence of incorporation of $\mathrm{ZnO}$ nanoparticles and biaxial orientation on mechanical and oxygen barrier properties of polypropylene films for food packaging applications. J. Appl. Polym. Sci. 2011, 120, 1616-1623. [CrossRef]

22. Hu, G.; Ma, Y.; Wang, B. Mechanical properties and morphology of nylon 11/tetrapod-shaped zinc oxide whisker composite. Mater. Sci. Eng. A 2009, 504, 8-12. [CrossRef]

23. Zhang, G.; Liu, Y.; Morikawa, H.; Chen, Y. Application of ZnO nanoparticles to enhance the antimicrobial activity; and ultraviolet protective property of bamboo pulp fabric. Cellulose 2013, 20, 1877-1884. [CrossRef]

24. Zhang, D.; Zhang, G.; Ling, C.; Liao, Y.; Chen, Y.; Hong, L.; Morikawa, H. Synthesis of ZnO nanoparticles by PNP and its application on the functional finishing of cotton fabrics. Fibers Polym. 2014, 15, 1842-1849. [CrossRef]

25. Saliba, S.; Valverde Serrano, C.; Keilitz, J.; Kahn, M.L.; Mingotaud, C.; Haag, R.; Marty, J.-D. Hyperbranched polymers for the formation and stabilization of $\mathrm{ZnO}$ nanoparticles. Chem. Mater. 2010, 22, 6301-6309. [CrossRef]

26. Gao, H.; Yorifuji, D.; Wakita, J.; Jiang, Z.-H.; Ando, S. In situ preparation of nano ZnO/hyperbranched polyimide hybrid film and their optical properties. Polymer 2010, 51, 3173-3180. [CrossRef]

27. Zeng, Y.; Chen, X.; Yi, Z.; Yi, Y.; Xu, X. Fabrication of pn heterostructure ZnO/Si moth-eye structures: Antireflection, enhanced charge separation and photocatalytic properties. Appl. Surf. Sci. 2018, 441, 40-48. [CrossRef]

28. Wang, M.; Li, A.-D.; Kong, J.-Z.; Gong, Y.-P.; Zhao, C.; Tang, Y.-F.; Wu, D. Fabrication and characterization of ZnO nano-clips by the polyol-mediated process. Nanoscale Res. Lett. 2018, 13, 47. [CrossRef]

29. Achehboune, M.; Khenfouch, M.; Boukhoubza, I.; Mothudi, B.; Zorkani, I.; Jorio, A. Structural and optical characterization of Holmium coated ZnO nanorods. J. Phys. Conf. Ser. 2018, 1, 012007. [CrossRef] 
30. Chandramouleeswaran, S.; Mhaske, S.T.; Kathe, A.A.; Varadarajan, P.V.; Prasad, V.; Vigneshwaran, N. Functional behaviour of polypropylene/ZnO-soluble starch nanocomposites. Nanotechnology 2007, 18, 385702. [CrossRef]

31. Zhang, H.; Hortal, M.; Jordá-Beneyto, M.; Rosa, E.; Lara-Lledo, M.; Lorente, I. ZnO-PLA nano composite coated paper for antimicrobial packaging application. LWT Food Sci. Technol. 2017, 78, 250-257. [CrossRef]

(C) 2019 by the authors. Licensee MDPI, Basel, Switzerland. This article is an open access article distributed under the terms and conditions of the Creative Commons Attribution (CC BY) license (http://creativecommons.org/licenses/by/4.0/). 